\title{
Los Derechos exclusivos del Estado, sobre los productos naturales de su plataforma*.
}

\author{
Alfredo Eisenberg \\ Professor Adjunto de Direito Internacional \\ Público na Facủldade de Direïto de \\ Montevideo.
}

Derechos Exclusivos -- Esta expresión sólo corresponde a lo estatuído en el párrafo 2 del Art. 2 e la Convención sôbre Plataforma Continental. Nadie puede emprender exploración y/o explotación de los recursos naturales de la plataforma continental sin el consentimiento del Estado ribereño, aún en el caso de que el Estado no emprenda esas actividades.

Ante todo es preciso distinguir esta exclusividad de derechos, con la preconizada al discutirse el párrafo primero del mismo art.. En efecto, en el art. 68 del proyecto de la Comisión de Derecho Internacional de las Naciones Unidas, se hablaba de que el Estado ribereño tenía "derechos de soberanía", pero sólo en el ejercicio para el propósito de explorar y explotar sus recursos naturales. En esta redacción, que quedó en definitiva incorporada a la Convención, se trasluce la inequivoca determinación de la Mayoría, de no conceder soberanía, como lo proponían las delegaciones de México y Argentina, sobre la plataforma, y por onde, sobre sus recursos naturales, sin limi-

* Tese apresentada às "II Jornadas Uruguaio-Brasileiras de Direito Comparado", realizadas na Faculdade de Direito da Universidade de São Paulo. 
taciones de ninguna especie. Lá fórmula es transaccional, y a ella se legó tras largo debate, y cambios importantes de argumentos y de posición de parte de Estados vitalmente interesados en la cuestión. El proyecto original de la C.D.I.N.u. admitia derechos de "autoridad y control" sobre la plataforma continental de parte del Estado ribereño, (por influjo de la proclama Truman). Pero esas locuciones podían llevar a pensar que eran expresión de soberanía "per se". De allí el cambio, otorgar derechos de soberanía, pero precisamente delimitados: sólo y nada más que para exploración y/o explotación de los recursos de la plataforma.

En la Cuarta Comisión, que en Ginebra estudió el punto, se aprobó, por 21 votos contra 20 y 27 abstenciones, la emienda de los E.E.u.v. ${ }^{1}$ que sustituía "de soberanía", por "exclusivos". Lo que se quizo con esta enmienda 10 manifestó la delegado de ese país, Sra. Whiteman:

"Con el objeto de poner de manifiesto que las aguas situadas encima de la plataforma continental no quedan afectadas en absoluto, la delegación de los Estados Unidos desearía que se suprimieran las palabras "de soberanía", aún quando está de acuerdo en que se conserve la palabra "derechos".

En el plenario, la delegación norteamericana votó finalmente la proposición hindú, volviendo a “derechos de soberanía"2. Proposición ésta aprobada en definitiva, por 51 votos contra 14 y 6 abstenciones. Para García Amador, de Cuba, que actuó como portavoz oficioso de la tendencia de la G.D.I.N.U., la proyección de competencia del Estado ribereño sobre la plataforma era rigurosamente especializada, pero al mismo tiempo de carácter soberano ${ }^{3}$.

1. Doc. C4/L. 31 .

2. Doc. of., Vol. II p. 15 y 16.

3. Carlos Carbajal, La Plataforma Continental en la Conferencia de Genebra. Montevideo 1959, p. 66. 
En suma, en cuanto a la naturaleza juridica de los derechos del Estado ribereño o costero sobre la plataforma continental, la soberania ha sido distinguida de los derechos soberanos. En cuanto a la soberanía, tesis preconizada por la mayoria de los Estados latino-americanos, en su aspecto negativo, es el rechazo de las pretenciones de otros Estados de intervenir en el ejercicio de sus funciones por parte de un Estado ${ }^{4}$. Aunque etimológicamente equivalga a un grado de superioridad ${ }^{5}$, en el ámbito internacional, es "... independencia sujeta a Derecho" ". Implica, no sólo el ejercicio de derechos en que el Estado se evidencia dueño territorial, sino que, actuando, goza, en tal actuación, de los derechos y privilegios internacionales de orden público del Estado soberano ${ }^{7}$. No por ello ha de confundirse con la extensión de un derecho territorial, desde que tanto éste último como la soberanía, son del ser del Estado. La soberania se traduce, normalmente en un hacer, o en un impedir hacer a los demás Estados, en su ámbito de acción, de acuerdo al Derecho.

Los derechos soberanos, en cambio, tesis de la mayoria, si bien incluyen todas las potestades que pudieren ser necessarias al Estado costero para utilizar la plataforma, como el otorgamiento de concesiones, la legislación para prevenir o reprimir las infracciones a esas leyes, son expresamente limitados y caracterizados en su contenido y alcance. De alli que su interpretación sea estricta. Los derechos exclusivos aparecen entonces como caracterización de eses derechos de soberania, como atributo.

4. S. Hoffmann, Organisations Internationales et Pouvoirs Politiques des Etats. Paris 1954, p. 12.

5. JASPAR, Staats. Annales de Droit et Sciences Politiques, Belgique t. X, n. 42 p. 408.

6. H. BRIGGs, Powers Politics and International Organisation A.J.I.L., v. 39, 1945 , p. 664.

7. A. RAestad, Souveraineté et D. Int. (1936), 17 R.D.I., p. 54. 
a). a que alcanza la exclusividad - La exclusividad es entendida en el sentido de que se necesita, en todos los casos, haya o no actividad del Estado ribereño en ese sentido, la manifestación expressa inequívoca, del estado riberenõ para explorar o explotar, o aún reivindicar la plataforma. Esta redacción, debida al delegado argentino introduce una verdadera gradación, pues ante todo, la reivindicación parece prever el caso de explotación de la plataforma por parte de otro Estado que el costero, en cuyo no puede valerse de ese hecho para nada. No debe olvidarse que el párrafo 3 del art. 2 expresa que para nada afectan a los derechos del ribereño la falta de declaración expresa y/o de ocupación real o ficta. Tales derechos son independientes por completo de toda expresión formal. Sen, de la esencia misma del Estado costero, por la posición que ocupa respecto de la Plataforma. Ambas nociones sirven para descartar, de una vez y para siempre, la equivocada tesis, sostenida ambiguamente por la doctrina inglesa, o al menos parte de la misma, de que la plataforma continental, más alla de las aguas territoriales, consideradas en su más mínima expresión, era "res nullius". En cuanto a la exploración, es previa como etapa, a la explotación. No deja de ser significativo el interés del proponente, por quanto fué uno de los propugnadores más tenaces de la tesis de la soberanía total del Estado ribereño sobre la Plataforma.

Los Productos Naturales: - Este es el punto crucial. Pues es sólo para su explotación que el Estado costero tiene derechos exclusivos.

No parece necesario referirse a los recursos minerales y otros recursos no vivos del lecho del mar y del subsuelo. El párrafo 4 del art. 2 de la Convención es suficientemente claro y explicito, y por lo demás no se plantean ver-

8. Veáse. C. Hurst en Collected papers, 1950, pp. 51-61 y c/s. con esta tesis OPPENHEIM - LAUTERPACH 7. ${ }^{a}$ ed., v. 1 pp. 576-8 et. . 
daderos problemas en cuanto a su alcance. Pero en cambio, sí se plantean problemas, y de suma importancia sobre la segunda parte de dicho párrafo, en cuanto podría afectar, en ciertas interpretaciones, ciertos tipos de pesoa verdaderamente importantes, en especial modo para los países latinoamericanos.

Dice en su segunda parte el párrafo 4 del Art. 2, refiriéndose a lo que se entiende por "recursos naturales":

“ .Dicha expresión comprende, asimismo, los organismos vivos, pertenecientes a especies sedentarias, es decir, aquelles que en el período de explotación están inmóviles en el lecho del mar o en su subsuelo, o sólo pueden moverse en constante contacto físico con dicho lecho y subsuelo".

En verdad, la c.D.I.N.U. fue siempre consecuente con la tesis de que las llamadas pesquerias sedentarias, pues su relación con el lecho del mar es de caráter permanente. Así, las ostras, corales, etc. entrarian en la definición sin verdadero problema de interpretación o extensión. El delegado australiano señalo, en Comisión, que entrarian en esa definición de especies sedentarias: el coral, las esponjas, las ostras, con inclusión de las perlíferas, las madreperlas, la turbinella sagrada dela India y de Ceilán, el trocure y las plantas 9 .

Fundamental aparece, en cambio, el trámite de una enmienda conjunta preconizada en la Comisión por Australia, Ceilán, Federación Malaya, India, Noruega y Reino Unido. En ella, no se comprendian en las especies sedentarias, en forma expresa, los "crustáceos y las especies que nadan en las aguas". A pesar de que México propuso, en enmienda oral suprimir las palabras "los crustáceos " $y$ ", la proposición, con ese agregado, fué aprobada en Comisión por 41 votos contra 11 y 17 abstenciones. Pero en el Plena-

9. T. vI, pp. 67 y 68 . 
rio de la Conferencia, El Salvador propuso se votara separadamente sobre las palabras "crustáceos " $y$ " del párrafo 4. Y la Conferencia, por 42 votos contra 22 y 66 abstenciones rechazó tales palabras. Per otra parte, Reino Unido propuso similar criterio con las palabras "las especies natatorias no están comprendidas en la anterior definición":

"...para eliminar una fuente posible de futuras desavenencias

...pues cabe concebir que llegue a incluirse en su significado a los crustáceos natatorios"10.

Estas palabras fueron eliminadas por 43 votos contra 14 y 9 abstenciones.

Ante todo, en cuanto a los crustáceos, y las especies natatorias, es preciso senãlar que de la tramitación surge, a nuestro entender, que la supresión se debió a la voluntad de la Conferencia de que esas especies podían integrar las especies sedentarias, siempre que se diesen los presupuestos básicos de su caracterización. Aún más, con un criterio rigoroso, hasta podría sostenerse que las entendió comprendidas, a 10 menos en los crustáceos, por su propia naturaleza. De ningún modo podrá aceptarse la tesis sostenida por la Sra. GuTteridge de que la eliminación de estos términos fúe hecha porque aparecian como supérfluos ${ }^{11}$. Nada permite suponer ese a través del contexto de discusión y votaciones en el plenario. Más aún. La interpretación sin violencias, y sin extremos, da el resultado contrario. Más peregrina es la acepción que cree encontrar la delegado de E.E.u.u. Sra. Whiteman, de que la interpretación que prima es la del proponente, Australia, que sostenía que la eliminación se debió a ser supérflua su inclusión ${ }^{12}$. Cabe preguntarse porqué no se tomó más bien

10. v. II p. 16.

11. En B. Y-B.I.L. 1959 p. 118.

12. En A.J.I.L. 1958 p. 638. 
como proponente al de la eliminación, primero México y luego El Salvador, éste último con éxito en el Plenario. No parece difícil la respuesta, sobre todo conociendo la opinión sustentada por estos países. Para ellos, los crustáceos son parte de los recursos naturales de la plataforma.

En verdad la fórmula final y consagrada tiene un carácter temporal en cuanto se refiere al período de explotación, pero éste ha de ser determinado por los técnicos. La interpretación de la Comisión de que sería el momento en que fuesen las especies, susceptibles de explotación, y no el momento mismo de la pesca, no puede ser tomado como absoluto aunque es un indice persuasivo. La movilidad se refiere sólamente, desde luego, al constante contacto físico con el lecho del mar. Esa constancia no impide que el crustaceo se desplace en grandes distancias. No por ello se agota la problemática, pero es preciso expresar que en esta materia se hace necesario dar la prioridad a los científicos, y luego interpretar jurídicamente sus resultados. Sin dejar de hacer notar que constante no es permanente, e implica la posibilitad de un desplazamiento por cualquier medio y en cualquier forma, bastando el contacto regular en el tiempo con el lecho. No necesitamos subrayar la importancia de ésta interpretación que creemos es la correcta. 